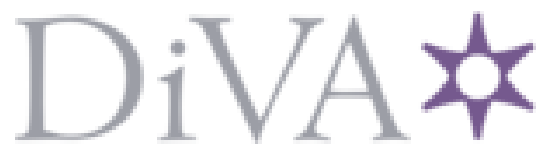

http://www.diva-portal.org

This is the published version of a chapter published in Negotiating the intersections of writing and writing instruction.

Citation for the original published chapter:

Vandermeulen, N., Meulemans, C., Paesen, L., Limpo, T. (2022)

A reflection on academic writing: the perspective of a group of European writing researchers

In: Magnus Gustafsson; Andreas Eriksson (ed.), Negotiating the intersections of writing and writing instruction (pp. 293-299). The WAC Clearinghouse; University Press of Colorado

International Exchanges on the Study of Writing

https://doi.org/DOI: 10.37514/INT-B.2022.1466.2.12

N.B. When citing this work, cite the original published chapter.

This work is licensed under a Creative Commons Attribution-NonCommercial-NoDerivatives 4.0 International License.

Permanent link to this version:

http://urn.kb.se/resolve?urn=urn:nbn:se:umu:diva-192088 


\title{
12 A Reflection on Academic Writing: The Perspective of a Group of European Writing Researchers
}

\author{
Nina Vandermeulen \\ UMEÅ UNIVERSITY \\ Catherine Meulemans \\ University of ANTwerp \\ Lise Paesen \\ KdG University of Applied Sciences and Arts \\ Teresa Limpo \\ University of Porto
}

In addition to being writing researchers, a common feature of the authors of this chapter is that they all belong to the Special Interest Group (SIG) on Writing. SIG Writing is a multidisciplinary organization promoting research on writing and providing a forum for exchange of ideas and collaboration. The organization was founded in 1988 as the $\mathrm{I}^{\text {th }}$ Special Interest Group of the European Association for Research on Learning and Instruction (EARLI). Through a biannual conference (SIG Writing conference), publications (Journal of Writing Research and the Studies in Writing book series), and several national writing initiatives, SIG Writing aims to promote collaboration between writing researchers from various countries and from various disciplines. SIG Writing members carry out research on a variety of writing related topics from theoretical, empirical and practice-based perspectives. One of the topics that is rather well represented within the SIG Writing community is academic writing. When going over the contributions of the past SIG Writing conferences, it seems that about fifteen percent of the total contributions targets themes related to academic writing.

In this reflection, we will touch upon a few academic writing related topics present in recent research of SIG Writing members and in this way, we will draw parallels with the European Association for the Teaching of Academic Writing (EATAW). Firstly, we reflect on the importance of writing process 
studies, both from a social and a cognitive point of view. Secondly, we look into writing beliefs and writer identity, which is a main topic in academic writing studies. Thirdly, we present a short reflection on the growing interest for a specific type of academic writing, namely, writing based on sources.

\section{Writing Processes}

From primary school to university, writing primarily receives attention through the actual texts that are written (i.e., the end product): students' scores are based on the texts they produce and not on bow they produce the texts (Vandermeulen, 2020). However, in recent years, writing processes and the relationship between them and their resulting texts seem to gain more coverage. The attention to writing processes in this book is therefore much appreciated. Dengscherz' chapter proposes the PROSIMS writing process model that looks at the influence of individual and situational factors on the writing situations that shape the writing process. This approach also takes into account the interrelations between writing activities and a large number of factors, such as task requirements and writers' strategies, providing a powerful example of how to look at writing processes from a social perspective. In her chapter, Castelló proposes an original and interesting addition to this social perspective, by also considering the ways in which reviewers help to shape a text.

This social approach aligns with the pedagogical focus of EATAW research but contrasts with the rather cognitive approach, very common among SIG Writing members (Galbraith \& Baaijen, 20I9; Limpo, 20I8; Olive, 20I4; Paesen \& Leijten, 2019). While the social approach adopts a macro perspective and usually studies how the writing context influences texts from one version to the next, the cognitive approach tends to adopt a more micro approach concerned with the writing processes, for example by looking at the moment-to-moment production of a text. Typically, researchers opt to follow the text formation closely, using synchronous software to record keystrokes (e.g., Inputlog, Leijten \& Van Waes, 20I3; ScriptLog, Frid et al., 2014) or handwriting movements (e.g., Eye and Pen, Alamargot et al., 2006). When combined with other methods such as eye tracking, the writing process patterns give insight into several cognitive processes (i.e., planning, translating, reviewing, and transcription) (Wengelin et al., 2009).

Castelló briefly mentions the additional use of keystroke logging and screen capture software for one case study and thus provides an example of how the EATAW and SIG Writing perspectives can complement and reinforce each other. In future research, we would like to encourage bringing 
together the social nature and the cognitive aspect of writing. For example, studies focusing on language disabilities (e.g., dyslexia) would benefit from looking at the writing process from a cognitive point of view combined with a practice-oriented component. This would address the need to both understand certain language problems as well as to provide practical solutions for addressing them. It would be particularly helpful for university writing centers that offer support to undergraduates with language disabilities.

\section{Writing Beliefs and Writer Identity}

Besides an attention to academic writing products and processes, studies in writing also focus on the personal and social settings of writing. Writing beliefs and writer identity were two of the related and recurrent themes within research on academic writing of the last SIG Writing conferences. It is very encouraging to see the shared interest of EATAW and SIG Writing on this topic. The chapters provided by Dengscherz and Machura show a nice variety in studies with a focus on writing beliefs. Dengscherz presents a writing process model that considers individual variation in writing processes by taking into account attitudes, self-perception, motivation and beliefs. This study presents a more theoretical perspective, though one with implications for a more practical approach. Machura presents a pedagogically oriented approach. She presents an intervention study that resulted in substantial changes in participants' writing beliefs and attitudes.

Studies presented at SIG Writing conferences or published within Journal of Writing Research have focused on the link between writers' beliefs on writing and the strategies or approaches they adopt during the writing process when writing an academic text (Cuevas et al., 20I8; Hewitt, 20I8). Consequently, writing beliefs also influence the quality of the final text (Galbraith, 20I8; Neely, 20I4). Intervention studies to promote academic writing such as the ones by Wischgoll and Klingsieck (20I8) and Strobl (2014) tested the effect of strategy instruction on text quality and writing beliefs (including writing approaches, strategies, and self-efficacy). These studies provide evidence for the beneficial impact of interventions targeting undergraduate students' writing beliefs. In the future, more intervention studies could be set up, based on insights from the various theoretically oriented studies, as a deeper understanding of the connection between writing beliefs, writing processes and text quality brings to light important elements that can be targeted in writing instruction on academic writing.

In addition to writing beliefs, there is also a representative body of work on the writer's identity in this collection. Castelló's chapter highlights the im- 
portance of acknowledging other voices while differentiating a personal voice in developing an academic writer identity. In addition, the work of Ankersborg and Pogner recognizes the importance of students becoming aware of their learner and writer identity as part of a student-supervisor model for thesis writing. Also within the SIG Writing community, there is a research interest for writer identity. For example, a symposium bringing together work of Donahue, Maguire, and Jeffery (Spelman, 2014) mapped the development of writer identity in settings of the transition from secondary education to higher education, meanwhile taking into account a wide personal and social context. An interesting niche within writer identity research focuses on writer identity of professional academic writers, such as doctoral and postdoctoral researchers (Rubin, 20I8; Skakni, 20I8). Insights from these studies could be very valuable to shape writing training sessions as part of universities' doctoral programs.

\section{Source-based Writing}

We would like to reflect on a specific type of academic writing, namely, sourcebased writing, sometimes also referred to as synthesis writing. Source-based writing is gaining attention in recent writing research as it is a fundamental skill in upper-secondary and higher education. Writing a text that integrates the content of multiple sources involves a complex interplay of reading and writing activities, and thus poses a challenge for students. Intensive writing training sessions such as the ones proposed by Machura in this book, are most valuable to support students in developing their source-based writing skills. This study is a great example of an evidence-based intervention with a pedagogical aim.

Within SIG Writing, two main areas of source-based writing research can be distinguished: a theoretically and a pedagogically oriented approach. Escorcia (2018), Leijten et al. (2019), and Vandermeulen et al. (2020) mapped synthesis writing processes, focusing on reading and writing strategies and the use of sources during writing. These types of studies provide theoretical insights into source-based writing, which in their turn can give input to more educationally focused studies and implementations. Intervention studies-both online (Luna et al., 2020; Strobl, 20I4;) and offline (Cuevas et al., 20I8; Raedts \& Rijlaarsdam, 20I2)—aimed to improve students' writing. They showed the positive effect of instructional methods such as explicit strategy instruction, guided exercises, graphic organizers, and video modeling on the students' synthesis text quality. 


\section{Conclusion}

When going through EATAW's work, the organization's goal of making the link between research and practice definitely catches the eye. Academic research having an impact on academic practice might seem obvious, but in day-to-day practice, it is far from evident. Though educators in higher education generally show a positive attitude towards evidence-based practice, they also find it challenging and point to the need for more support in bridging the gap from research to practice (Diery et al., 2020). EATAW's mission to connect the teachers and scholars of academic writing is thus extremely valuable. This is well illustrated in the present book volume of EATAW, which provides a comprehensive perspective on current studies focusing on the teaching of academic writing from multiple viewpoints.

In this contribution, we highlighted three recurrent themes in academic writing research from our perspective as researchers within the SIG Writing community. Though the research within the SIG Writing organization covers a wide range of topics, studies on academic writing are well represented at the biannual conferences, as illustrated above. While reflecting on writing processes, writing beliefs, and source-based writing within the field of academic writing, we drew some parallels between the work of EATAW and SIG Writing that may stimulate collaborative works between the two organizations.

Despite the increasing amount of research focusing on teaching academic writing, there are still many avenues that can be taken for that joint research in the future. The three academic writing related subtopics that we highlighted in this reflection point to possible directions for that. Combining various perspectives like a product and a process approach provides valuable insights that will lead to a deeper understanding of academic writing. Additionally, there is the attention to writer-related characteristics such as writing beliefs and writer identity that adds to the teaching of academic writing. Our third subtopic, namely source-based writing, constitutes an example of a complex academic writing task in upper-secondary and higher education for which students need support. With changing student populations, varying university agendas, and shifts in teaching modes, there will be a need to continue developing and adapting evidence-based practice. A recent example calling for more research and a bridge to practice is the rise of remote teaching.

We believe combining perspectives of different fields and various methodological approaches, which complement each other, is fundamental to gaining relevant insights into both theory and practice of academic writing. We do hope this chapter was another step forward to that end. 


\section{References}

Alamargot, D., Chesnet, D., Dansac, C., \& Ros, C. (2006). Eye and pen: A new device for studying reading during writing. Behavior Research Methods, 38(2), 287-299. https://doi.org/10.3758/BF03192780

Cuevas, I., Mateos M., \& Martín, E. (2018, August 29-31). Teaching to write argumentative synthesis collaboratively in higher education [Paper presentation]. SIG Writing Conference, Antwerp, Belgium.

Diery, A., Vogel, F., Knogler, M., \& Seidel, T. (2020). Evidence-based practice in higher education: Teacher educators' attitudes, challenges, and uses. Frontiers in Education, 5. https://doi.org/10.3389/feduc.2020.00062

Escorcia, D. (2018, August 29-31). Writing and reading strategies when producing texts in bigher education [Paper presentation]. SIG Writing Conference, Antwerp, Belgium.

Frid, J., Johansson, V., Johansson, R., \& Wengelin, Å. (2014, February 19-22). Developing a keystroke logging program into a writing experiment environment [Paper presentation]. WRAB Conference, Paris, France.

Galbraith, D. (2018, August 29-31). Identifying writing beliefs [Paper presentation]. SIG Writing Conference, Antwerp, Belgium.

Galbraith, D., \& Baaijen, V. M. (2019). Aligning keystrokes with cognitive processes in writing. In E. Lindgren \& K. Sullivan (Eds.), Observing writing. Insights from keystroke logging and handwriting (pp. 306-325). Brill. https://doi. org/10.1163/9789004392526_015

Hewitt, C. (2018, August 26-28). Not writing from the heart: Exploring the relationship between students' beliefs about academic writing and the approaches they adopt [Paper presentation]. SIG Writing Research School, Ghent, Belgium.

Leijten, M., \& Van Waes, L. (2013). Keystroke logging in writing research: Using inputlog to analyze and visualize writing processes. Written Communication, 30(3), 358-392. https://doi.org/10.1177/0741088313491692

Leijten, M., Van Waes, L., Schrijver, I., Bernolet, S., \& Vangehuchten, L. (2019). Mapping master's students' use of external sources in source-based writing in L1 and L2. Studies in Second Language Acquisition, 41(3), 555-582. https://doi. org/10.1017/s0272263119000251

Limpo, T. (2018). Development of a short measure of writing apprehension: Validity evidence and association with writing frequency, process, and performance. Learning \& Instruction, 58, 115-125. https://doi.org/10.1016/j. learninstruc.2019.101272

Luna, M., Villalón, R., Mateos, M., \& Martín, E. (2020). Improving university argumentative writing through online training. Journal of Writing Research, 12(1), 233-262. https://doi.org/10.17239/jowr-2020.12.01.08

Neely, M. E. (2014). Epistemological and writing beliefs in a first-year college writing course: Exploring shifts across a semester and relationships with argument quality. Journal of Writing Research, 6(2), 141-170. https://doi. org/10.17239/jowr-2014.06.02.3 
Olive, T. (2014). Toward a parallel and cascading model of the writing system: A review of research on writing processes coordination. Journal of Writing Research, 6(2), 141-171. https://doi.org/10.17239/jowr-2014.06.02.4

Paesen, L., \& Leijten, M. (2019). Name agreement and naming latencies for typed picture naming in aging adults. Clinical Linguistics and Phonetics, 33(10-11), 930948. https://doi.org/10.1080/02699206.2019.1590734

Raedts, M., \& Rijlaarsdam, G. (2012, July 10-13). Influence of writing instruction and cognitive skills on undergraduate students' academic writing [Paper presentation]. SIG Writing Conference, Porto, Portugal.

Rubin, H. (2018, August 29-31). Academics' plurilingual voice: Fostering creativity in writing [Paper presentation]. SIG Writing Conference, Antwerp, Belgium.

Skakni, I. (2018, August 29-31). Early career researchers and academic writing: $A$ love-hate relationship? [Paper presentation]. SIG Writing Conference, Antwerp, Belgium.

Spelman, K. (2014, August 27-29). Transitions in writing: Perspectives from academic and social contexts [Symposium]. SIG Writing Conference, Amsterdam, Netherlands.

Strobl, C. (2014, August 27-29). The effect of online collaboration of individual academic writing development in a foreign language: Discussing a discrepancy between analysis results of writing process and product [Paper presentation]. SIG Writing Conference, Amsterdam, Netherlands.

Vandermeulen, N., Van Steendam, E., van den Broek, B., \& Rijlaarsdam, G. (2020). In search of an effective source use pattern for writing argumentative and informative synthesis texts. Reading and Writing, 33(2), 239-266. https://doi. org/10.1007/s11145-019-09958-3

Wengelin, Å., Torrance, M., Holmqvist, K., Simpson, S., Galbraith, D., Johansson, V., \& Johansson, R. (2009). Combined eyetracking and keystroke-logging methods for studying cognitive processes in text production. Behavior Research Methods, 41(2), 337-351. https://doi.org/10.3758/BRM.41.2.337

Wischgoll, A., \& Klingsieck, K. (2018, August 29-31). Effects of (meta)cognitive strategy instruction on self-efficacy, writing beliefs, and text quality [Paper presentation]. SIG Writing Conference, Antwerp. 